\section{AMÉRICA LATINA Y LA HISTORIOGRAFÍA DEL DERECHO PENAL INTERNACIONAL}

\author{
LATIN AMERICA AND THE HISTORIOGRAPHY \\ OF INTERNATIONAL CRIMINAL LAW
}

\section{FRANCISCO JOSÉ QUINTANA ·}

Doctorando en Derecho Internacional y Becario Gates

Cambridge, University of Cambridge (Reino Unido).

email: fjq20@cam.ac.uk

\section{Resumen}

Este artículo explora la relación entre la historia del derecho penal internacional, el giro histórico en el derecho internacional y América Latina. Argumenta que la «narrativa del manual» ha facilitado la justificación del proyecto del derecho penal internacional, a expensas de difundir una historia simplista que asume que la disciplina ha existido en su forma actual desde, al menos, la posguerra de la Segunda Guerra Mundial. El artículo muestra cómo esta narrativa ha comenzado a ser desafiada por el giro histórico en el derecho internacional, que ha infundido una preocupación metodológica al estudio del derecho internacional en general. Por último, el artículo argumenta que la exclusión de ciertos desarrollos que tuvieron lugar en América Latina durante las transiciones a la democracia a partir de la década de 1980 de la historia convencional del derecho penal internacional señala ciertos problemas significativos en la historiografía de la disciplina.

\section{Registro bibliográfico}

QUINTANA, FRANCISCO JOSÉ «América Latina y la historiografía del derecho penal internacional», en: ESTUDIOS SOCIALES, revista universitaria semestral, año XXX, $n^{\circ} 59$, Santa Fe, Argentina, Universidad Nacional del Litoral, julio-diciembre, 2020, pp. 63-87.

\section{Abstract}

This article explores the relationship between the history of international criminal law, the historical turn in international law, and Latin America. The article argues that the «textbook narrative» has facilitated the justification of the project of international criminal law at the expense of spreading a simplistic history that assumes that the discipline has existed in its actual form since, at least, the aftermath of World War II. The article shows how this narrative has begun to be challenged by the historical turn in international law, which has instilled a methodological concern to international legal scholarship broadly. Finally, this article argues that the exclusion of certain developments that took place in Latin America during the transitions to democracy starting in the 1980s from the conventional history of international criminal law points to a number of significative problems in the historiography of the discipline.

\section{Descriptores · Describers}

Derecho penal internacional / historia del derecho internacional / América Latina / estudios críticos / derechos humanos

International criminal law / history of international law / Latin America / critical approaches / human rights

Recibido: 31 / $10 / 2018$ Aprobado: 22 / 05 / 2020 


\section{INTRODUCCIÓN}

La historia ocupa un rol prominente en el discurso de los académicos y practicantes del derecho penal internacional ${ }^{1}$. Las referencias a Núremberg o, en menor medida, a los orígenes del Tribunal Penal Internacional para la ex Yugoslavia son frecuentes en alegatos, en debates en organizaciones internacionales y en las primeras páginas de libros o artículos académicos, incluso entre aquellos que abordan cuestiones sumamente específicas. Estas referencias suelen inscribirse dentro de una narrativa que ha sido, al menos hasta tiempos recientes, sorprendentemente uniforme. Entre muchas regiones y espacios ausentes en esta narrativa, se encuentra América Latina.

Este artículo explora la relación entre la historia del derecho penal internacional, el giro histórico en el derecho internacional y América Latina. Argumenta que la «narrativa del manual» ha facilitado la justificación del proyecto del derecho penal internacional, a expensas de difundir una historia simplista que asume que la disciplina ha existido en su forma actual sin grandes cambios desde, al menos, la posguerra de la Segunda Guerra Mundial. El artículo muestra cómo esta narrativa ha comenzado a ser desafiada por el giro histórico en el derecho internacional, que ha infundido una preocupación metodológica al estudio del derecho internacional en general, aunque con menor fuerza en el derecho penal internacional que en otras subdisciplinas. Por último, el artículo argumenta que la exclusión de ciertos desarrollos que tuvieron lugar en América Latina durante las transiciones a la democracia a partir de la década de 1980 de la historia convencional del derecho penal internacional sugiere problemas significativos en la historiografía de la disciplina; en particular, señala una falta de atención a causalidades de largo plazo, un apoyo en una distinción binaria entre lo internacional y lo doméstico, una propensión a la búsqueda de precedentes útiles (en sentido técnico y sentido figurado) y una perspectiva eurocéntrica.

El artículo adopta la siguiente estructura. La sección I, a continuación, reconstruye sucintamente la narrativa del manual del derecho penal internacional, introduce el concepto del giro histórico en el derecho internacional, y retrata las implicancias que este desarrollo plantea para la historiografía del derecho penal internacional describiendo tres enfoques revisionistas recientes. La sección II aborda una de las muchas exclusiones de la historia convencional del derecho penal internacional:

1] Agradezco a Alejandro Chehtman, Juan Pablo Scarfi, Justina Uriburu y a las/os evaluadoras/es anónimos por sus valiosos comentarios. 
la de las discusiones, respuestas y juicios por violaciones de los derechos humanos durante las transiciones democráticas en América Latina en la década de 1980; explora - y rechaza — ciertos argumentos que podrían justificar su exclusión y sugiere que esta exclusión señala también ciertos problemas en la historiografía del derecho penal internacional. Por último, la sección III concluye brevemente.

\section{EL DERECHO PENAL INTERNACIONAL Y LA HISTORIA}

La expresión más acabada de la narrativa tradicional del derecho penal internacional se encuentra en los capítulos dedicados a la historia en los manuales especializados. Como ha ocurrido en el campo de los derechos humanos (véase HALME-TUOMISAARI Y SLOTTE, 2OI5), la «narrativa del manual» le ofrece al derecho penal internacional un manto de legitimidad en la forma de un relato grandioso y teleológico. Esta narrativa es simple, simplista y, entre muchas exclusiones, ignora casi por completo a América Latina. Sin embargo, el «giro histórico» en el derecho internacional ha comenzado a complementarla, discutirla y desafiarla

\section{La narrativa del manual}

La narrativa del manual tiene dos rasgos definitorios. Estructuralmente, se concentra en resumir la historia del derecho penal internacional en un puñado de grandes eventos. Cronológicamente, presenta al derecho penal internacional como un proyecto que emergió después de la Segunda Guerra Mundial, fue congeladopor la Guerra Fría y retomado en la década de 1990. Con pequeñas variaciones, la mayoría de los manuales de la disciplina reproducen esta narrativa (véase, por ejemplo, AMBOS, 2OI3; BANTEKAS y NASH, 2007; BASSIOUNI, 20I3; CASSESE, 2008; CRYER ET AL., 2OI4). Existen, también, historias más desarrolladas con características similares (véase, por ejemplo, BASS, 2000; ROBERTSON, 2OI2).

De acuerdo con la narrativa del manual, el derecho penal internacional tiene un paso en falso como prehistoria: el intento de juzgar al Káiser Guillermo II tras la Primera Guerra. Efectivamente, los alemanes fueron demonizados desde el comienzo de la Gran Guerra y el Káiser comenzó paulatinamente a ser retratado como un criminal en los países aliados (HULL, 20I4; SIMPSON, 20I6). Tal es así que ya en 1918 Lloyd George se presentó a elecciones bajo un poderoso eslogan: «Cuel- 
guen al Káiser» (SIMPSON, 20I6: 5)². Finalizada la guerra, Gran Bretaña y Francia decidieron intentar juzgar penalmente al Káiser por haberla iniciado. Con este objetivo, los Aliados establecieron en Versalles una «Comisión sobre la Responsabilidad de los Autores de la Guerra» (COMMISSION ON THE RESPONSIBILITY OF THE AUthors of THEWAR AND ON ENFORCEMENT OF PENALITIES, 1920). La Comisión tendría a su cargo investigar e informar sobre «la responsabilidad de los autores de la guerra» (COMMISSION ON THE RESPONSIBILITY OF THE AUTHORS OF THE WAR AND ON ENFORCEMENT OF PENALITIES, I920: 95). Siguiendo las recomendaciones de la Comisión, el Tratado de Paz estableció en su artículo 227 que el Káiser sería juzgado por «el delito supremo contra la moralidad internacional y la santidad de los tratados» y que "un tribunal especial» sería establecido para juzgarlo. La narrativa tradicional suele resumir estos desarrollos en pocas oraciones y explica que este primer y loable intento fracasó cuando Holanda se negó a extraditar al Káiser (véase, por ejemplo, CRYER ET AL., 20I4: II6; BASSIOUNI, 20I3: IO52). La moraleja es que la falta de cooperación internacional aseguró la impunidad del Káiser. El fracaso de los procesos internos por crímenes de guerra en Leipzig, en los que sólo doce individuos fueron juzgados, confirma, en tanto, la importancia de encontrar respuestas a nivel internacional (ROBERTSON, 20I2: 557).

Tras este fallido intento, la narrativa tradicional saltea el período de entreguerras - uno de los más interesantes tanto en materia de construcción del derecho internacional moderno como de debates y propuestas alternativas infructuosas (véase BERMAN, I992; KENNEDY, 1987) - y se traslada a lo que presenta como el momento fundacional del derecho penal internacional: el juicio de Núremberg. Según esta visión, los horrores de la Segunda Guerra impulsaron a los aliados a cooperar en pos de la justicia internacional, dejando de lado el tipo de preocupaciones excesivas por la soberanía y el interés nacional que aseguraron la impunidad del Káiser. En palabras de Antonio Cassese, «fueron necesarias atrocidades de la magnitud de las cometidas durante la guerra para demostrar las nocivas consecuencias que pueden derivarse de la persecución de nociones extremas de soberanía estatal para forzar a la comunidad internacional a salir de su complacencia» (CASSESE, 2008: 320). Los cuatro poderes aliados firmaron entonces la Carta de Londres, estableciendo el Tribunal Militar Internacional de Núremberg. Sobre la base de este instrumento, a lo

2] Todas las traducciones del inglés me pertenecen. 
largo de diez meses, jueces y fiscales de los Estados Unidos, Francia, el Reino Unido y la Unión Soviética juzgaron a veinticuatro líderes nazis, condenando a veinte.

Meses después, el General MacArthur adoptó, a través de un decreto y en su carácter de Comandante Supremo de las Potencias Aliadas en el Pacífico, el Estatuto del Tribunal de Tokio. El fallo del Tribunal de Tokio fue duramente criticado por su apreciación de la prueba, su narración de los hechos y su aplicación del derecho, no sólo por diplomáticos y académicos, sino también por el Juez Pal en su voto disidente (PAL, 1953), que el General MacArthur ordenó no publicar (VARADARAJAN, 2OI4: 7). Quizás por este motivo, para la narrativa tradicional, al Tribunal de Tokio no hace falta mucho más que mencionarlo.

En noviembre de 1948 MacArthur confirmó el veredicto y las sentencias del Tribunal. Para entonces, en la visión tradicional, lo que parecía un ascenso galopante del derecho penal internacional comenzó a quedar congelado. Las experiencias de Núremberg y Tokio dejaron algunos resabios, incluyendo la adopción de la Convención contra el Genocidio en 1948, algunos aspectos de los Convenios de Ginebra de I949 y los juicios subsiguientes de Núremberg ante tribunales militares en la zona de ocupación estadounidense (véase HELLER, 20II). Luego vendría la muerte de Stalin, el recrudecimiento de la Guerra Fría y, según los manuales, el fin de la cooperación internacional con fines humanitarios y la suspensión del derecho penal internacional (BASsiouni, 20I3: 565). En palabras de James Crawford, «poco o nada se hizo» en materia de derecho penal internacional durante la Guerra Fría (CRAWFORD, 20I2: 674).

La narrativa tradicional reconoce algunas excepciones a la erradicación temporal del derecho penal internacional. La más notable es el juicio (y la posterior ejecución) de Adolf Eichmann en Israel, previo secuestro en San Fernando (Provincia de Buenos Aires) por parte del Mossad ${ }^{3}$. A este antecedente lo acompaña el trío de juicios contra Barbie, Touvier y Papon en la justicia francesa. Las referencias a América Latina son casi inexistentes. De hecho, estas excepciones tienen un punto en común: se trata de persecuciones contra exnazis. Estas excepciones no incomodan: no desafían la narrativa tradicional de un derecho penal internacional que depende de una cooperación internacional desinteresada y humanitaria para operar. Para esta narrativa, siguiendo a Gerry Simpson, los criminales nazis parecen jugar «un rol útil, demarcando un espacio aparentemente alejado de cualquier

3] El antecedente de Eichmann es, por ejemplo, mencionado en múltiples ocasiones en CASSESE, 2008; BASSIOUNI, 2013; CRYER ET AL., 2014. Sobre Eichmann, véase ARENDT, 1963. 
tipo de contienda ideológica» (SIMPson, 20I6: I6). El influyente manual de Cryer concluye: «hasta principios de los 90, parecía poco probable que cualquier progenie de Núremberg y Tokio fuera a aparecer» (CRYER ET AL., 2OI4: 127).

La caída del muro trajo «un eco de Núremberg» (scheffer, 20II: I5). Ante las imágenes televisadas alrededor del mundo de los que parecían ser campos de concentración en Bosnia, el Consejo de Seguridad de las Naciones Unidas estableció el TPIY en I993. Para Cassese, esto fue facilitado porque «los Estados sucesores de la URSS [...] finalmente mostraron mucho mayor respeto por el derecho internacional» (CASSESE, 2008, 324). El TPIY tendría la finalidad «de enjuiciar a los presuntos responsables de graves violaciones del derecho internacional humanitario» en la ex Yugoslavia ${ }^{4}$. Al año siguiente, el Consejo recurrió a la misma estrategia para lidiar con el genocidio ruandés, estableciendo el Tribunal Penal Internacional para Ruanda. Con la promocionada operación de ambos tribunales como trasfondo, en 1998, la policía británica arrestó a Pinochet en Londres por la presunta comisión de crímenes internacionales, sin consultar a las autoridades chilenas. El «momento Pinochet» señalaba el auge de la jurisdicción universal (schabAs, 20I6).

En 1998, en plena «luna de miel» del derecho penal internacional (LUBAN, 2OI3), I20 estados adoptaron el Estatuto de Roma, que estableció la primera Corte Penal Internacional permanente para "poner fin a la impunidad de los autores» de «los crímenes más graves» ${ }^{5}$. Veinte años después, la Corte ha abierto investigaciones en once situaciones (incluyendo Darfur y Libia), exámenes preliminares en muchas otras (incluyendo Afganistán y Colombia), y emitido órdenes de arresto contra dos jefes de Estado en funciones (al-Bashir y Gaddafi).

El derecho penal internacional se mantiene hoy como una disciplina relevante en el orden global. Los serios contratiempos que ha enfrentado la CPI (véase LUBAN, 2OI3) no disuaden por completo a los promotores de la disciplina: la narrativa les cuenta que el proyecto siempre ha enfrentado diversos problemas y los ha superado, que su horizonte siempre permaneció claro, que ha continuado desarrollándose paulatinamente y que lo seguirá haciendo siempre que exista voluntad genuina, y, fundamentalmente, que ha logrado resultados virtuosos (sobre cómo los especialistas en derecho penal internacional justifican la importancia de su disciplina, véase NOUwEN, 20I2).

4] Consejo de Seguridad, 25/05/1993, Res. 827, ONU DOC. S/RES/827.

5] Estatuto de Roma de la Corte Penal Internacional, ONU DOC. A/CONFR 183/9 (17 de Julio de 1998); preámbulo. 


\section{El «giro histórico» y el derecho penal internacional}

En el año 2002, Frédéric Mégret resumió claramente el rol de la historia en la literatura del derecho penal internacional: "parece ser un paso obligado para determinar la fortuna del derecho penal internacional; le proporciona al cuento la robustez de la edad y el carácter de lucha épica» (MÉGRET, 2002: I265). Al leer esta narrativa tradicional, no obstante —agregó Mégret—, uno no puede evitar pensar que «la justicia penal internacional debe contar también otra historia, una un poco más ambigua, más cargada de poder» (MÉGrET, 2002: I267).

Aun cuando en el derecho penal internacional se manifieste de forma especialmente fuerte, el problemade los usos de la historia ha marcado la trayectoria del derecho internacional en general. De hecho, el reconocimiento de que el derecho internacional ha estado dominado por historias idealizadas, lineares y descontextualizadas fue uno de los puntos de partida del denominado «giro histórico» de la disciplina, hacia fines de la década de 1990. Entonces, se produjo un renovado interés académico por revisar críticamente la historia de las estructuras, instituciones, figuras y prácticas del derecho internacional. Algunos trabajos de autores como Anthony Anghie, Martti Koskenniemi, Gerry Simpson y Liliana Obregón son a menudo identificados como el punto de inflexión que marca este giro (véase ANGHIE, 2005; KOSKENNIEMI, 2002; SIMPSON, 2004; OBREGÓN, 2006), que busca «desestabilizar las historias celebratorias del derecho internacional como una profesión que manifiestamente trabaja de forma colectiva a favor de los intereses comunes de la humanidad y de valores universales» (OXFORD, 20I7: 310; véase PITTS, 20I7).

Esta creciente producción histórica abarca líneas conceptuales diversas. A los TWAILers — los juristas que se identifican con las «Aproximaciones del Tercer Mundo al Derecho Internacional», mejor conocidas por sus siglas (en inglés) TwAIL (Third World Approaches to International Law) —, la historia les ha permitido exponer la persistente coconstitución entre el derecho internacional y el imperialismo, por ejemplo, mostrando cómo el encuentro colonial fue crucial para la formación del concepto de soberanía (ANGHIE, 2005; sobre TWAIL, véase ESLAVA y PAHUJA, 2OI2; véase también ESLAVA ETAL., 20I7). Otros autores se han posicionado directamente dentro de la tradición histórica y empleado principalmente método(s) histórico(s), con efectos críticos y conservadores (OXFORD, 20I7; véase también VADI, 20I7). Notablemente, la historia intelectual de la profesión del derecho internacional de Koskenniemi fue profundamente crítica al señalar al final del siglo diecinueve como el origen del derecho internacional moderno, y concentrarse en las empresas de 
juristas europeos con proyectos políticos como centrales para este desarrollo, y no en las figuras tradicionales de la disciplina como Grocio o Vitoria (KoskenNiEMI, 2002; véase LANG Y MARKS, 20I7: 325-326; BIANCHI, 20I6: I68-I72). En sus diversas variantes críticas, el giro histórico ha desplazado a los mitos fundacionales de la disciplina y facilitado el análisis de la relación entre el derecho internacional y el imperialismo, el racismo institucionalizado y la desigualdad internacional. Por otra parte, algunas de las historias TWAIL fueron denunciadas por historiadores como «anacrónicas» y excesivamente preocupadas por el presente, con efectos presumiblemente conservadores (OXFORD, 2013).

En general, el giro histórico ha inyectado al estudio del derecho internacional una sensibilidad metodológica que empuja a los juristas a justificar su método, sus fuentes y sus silencios. Las implicancias para el derecho penal internacional y su narrativa de manual son muchas. En el área de los derechos humanos, por ejemplo, una nueva historiografía floreció (véase, por ejemplo, MOYN, 2OIO; BARRETO, 2OI3; JENSEN, 2OI6; HOFFMANN, 2OI7; WHYTE, 2OI8; sobre la nueva historiografía, véase MOYN, 2OI2; SCARFI, 2OI7), en parte en reacción a las historias de manual, muchas de las cuales trazan los orígenes de los derechos humanos siglos o décadas atrás, y los retratan como un desarrollo inherentemente valioso que ha sido descubierto, antes que construido, y desarrollado de forma gradual. En particular, el trabajo del historiador y jurista Samuel Moyn, quien argumentó que los derechos humanos no constituyeron una agenda relevante para movimientos políticos ni aparecieron en el lenguaje popular antes de fines de la década de 1970, ha sido tan influyente como controversial (MOYN, 2OIO; sobre los problemas de este argumento, véase, por ejemplo, BARRETO, 20I8). A pesar de la riqueza de la discusión historiográfica en el campo de los derechos humanos, el giro histórico aún no se ha manifestado con suficiente fuerza en el campo del derecho penal internacional. Esto es llamativo, dada la relación que existe entre ambas disciplinas: el derecho penal internacional es habitualmente visto como un mecanismo para dar fuerza a las luchas de derechos humanos, a tal punto que apoyar a los derechos humanos a menudo parece conllevar apoyar la responsabilidad penal de aquellos individuos que participan en la comisión de atrocidades (ENGLE, 2015: IO70).

La narrativa dominante del derecho penal internacional refleja una problemática específica. Su estructura remite a aquellas historias de las ideas criticadas por Quentin Skinner por tomar como punto de partida una forma ideal de una doctrina determinada — en este caso, el ejercicio de justicia penal por parte de un 
tribunal internacional o supranacional, o el ejercicio de la jurisdicción universal por parte de un tribunal doméstico para juzgar al presunto autor de un crimen internacional - y salir a buscar manifestaciones de esta idea en el pasado, como si esta misma idea hubiese existido siempre, en su forma actual, a pesar de haber desaparecido de la vista en diversas ocasiones (SKINNER, 1969: IO). El giro histórico, o giro historiográfico, en el derecho internacional nos invita a preguntarnos: ¡es suficiente esta historia «jurisdiccional»? ¿Qué expresa? ¿Cómo se podría criticar, complementar o desafiar? Con menor fuerza que en otras subdisciplinas del derecho internacional, algunas perspectivas han comenzado a criticar la historiografía del derecho penal internacional y a ofrecer nuevas historias. Sin embargo, como advierte Immi Tallgren, en el derecho penal internacional los cuestionamientos metodológicos siguen siendo poco frecuentes (TALLGReN, 20I4: xvi; el propio ensayo de Tallgren es una excepción notable).

A continuación, identifico y presento tres perspectivas desde las cuales se ha comenzado recientemente a intentar repensar la historia del derecho penal internacional. Esta clasificación no es taxativa. Las perspectivas alternativas ilustran lo que está en juego en la construcción de la historia del derecho penal internacional, y el impacto que una mayor sensibilidad historiográfica ha tenido y puede tener en la disciplina. Estas exponen, por ejemplo, la falsa necesidad del derecho penal internacional sugerida por la narrativa de manual (véase UNGER, 200I); los ganadores y perdedores del proyecto del derecho penal internacional; y la dominancia del eurocentrismo.

\section{A. Historias ocultas}

Una primera y general perspectiva desde la cual se ha desafiado a la narrativa tradicional puede denominarse como "historias ocultas», en referencia al libro "The Hidden Histories of War Crimes Trials» editado por Kevin Heller y Gerry Simpson (HELler y SIMPSON, 20I3), aunque no es el único proyecto valioso de estas características (véanselas contribuciones al monumental «Historical Origins of International Criminal Law», en particular a los primeros dos volúmenes, BERGSMO $E T A L .$, 20I4). Esta perspectiva identifica y estudia diferentes eventos — típicamente juicios por atrocidades — que, por sus características, constituyen parte de la historia del derecho penal internacional pero que han sido ignorados.

Las implicancias históricas e historiográficas de este enfoque son diversas. En su versión más elemental, pueden ser una manifestación del problema descripto 
por Skinner antes que el comienzo de una solución: puede tratarse de eventos que poco tiene que ver con lo que hoy entendemos con derecho penal internacional, cuya inclusión se fuerza en la construcción de una historia. A pesar de este riesgo, este enfoque tiene potencial crítico. Como mínimo, las historias ocultas pueden contribuir a demostrar la selectividad de las narrativas dominantes.

El libro de Heller y Simpson es ilustrativo del potencial y de los límites de las «historias ocultas». Cada uno de sus capítulos se concentra en una instancia olvidada de «juicios por crímenes de guerra» (una muletilla que ha devenido imprecisa al no comprender los crímenes de lesa humanidad, el genocidio ni el crimen de agresión). Estos capítulos nos invitan a repensar la trayectoria del derecho penal internacional. Algunos proponen extender la línea del tiempo de la disciplina; por ejemplo, trazando paralelismos entre el derecho penal internacional moderno y juicios como el de Pedro de Hagenbach por un tribunal ad hoc del Sacro Imperio Romano en I474. Otros capítulos proponen prestar atención a algunos lugares más allá de La Haya, Núremberg y Tokio al analizar esta historia; por ejemplo, rescatan los juicios posteriores a la Segunda Guerra Mundial en Australia.

Como ha quedado claro del debate sobre el origen de los derechos humanos, las diferentes perspectivas historiográficas acerca de los orígenes de una disciplina suelen responder «a diferentes diagnósticos normativos acerca de [su] potencial y [sus] límites» (SCARFI, 20I7: 6). De este modo, identificar eventos ignorados en siglos pasados como señalando el origen antiguo del derecho penal internacional podría contribuir a establecer su necesidad, a sugerir que estos constituyen un aspecto fundamental o valioso para la realización del ser humano. No obstante, este enfoque no necesariamente implica una reivindicación del proyecto. Lo crucial no es simplemente entender cuándo surge una práctica o una disciplina, sino cómo.

Aunque algunos de los capítulos del libro de Heller y Simpson parecen inscribirse dentro de la corriente celebratoria, Simpson — autor de un importante libro crítico del derecho penal internacional (sIMPSON, 2007) — esboza en la introducción otros grupos de razones para identificar y estudiar eventos ignorados. Así, Simpson argumenta que concebir a estas instancias como parte de la disciplina contribuye a "des-europeizar» el derecho penal internacional (sIMPSON, 20I3: 3-4) y a entender que el derecho penal internacional no ha sido meramente improvisado sobre la marcha, sino que se ha beneficiado de importantes antecedentes históricos (sImpSON, 20I3: 5-6). Nuevamente, esto no debe verse necesariamente como reivindicatorio, en tanto sobreenfatizar la contingencia con objetivos críticos 
puede ser derrotista (sobre los peligros de la "falsa contingencia», véase MARKS 2009). Simpson agrega que estudiar estos sucesos ofrece beneficios pedagógicos al permitir contrastar debates contemporáneos sobre cuestiones que van desde la culpa colectiva de los pueblos hasta la autoría en el derecho penal con discusiones similares que tuvieron lugar en otros lugares, en otros tiempos (SIMPSON, 20I3: 6-7).

Ciertas formas de narrativas contraselectivas pueden contribuir al desarrollo de críticas duras a las concepciones más idealistas de la disciplina. Por ejemplo, al identificar precedentes problemáticos donde hoy hay historias de éxito o silencios, pueden romper con la periodización canónica y el relato evolucionista (véase, por ejemplo, SIMPSON 20I6: I6-I7, sobre el derecho penal internacional durante la Guerra Fría).

\section{B. Reconceptualización}

Una de las promesas más ambiciosas del creciente trabajo histórico en el derecho internacional es la de analizar cómo el derecho establece y dibuja fronteras entre diferentes áreas y conceptos jurídicos - lo público y lo privado; la soberanía y la propiedad - para desnaturalizarlas y exponer qué tipo de intereses apoyan (Koskenniemi, 20I8). Samuel Moyn ha propuesto una revisión de la historia del derecho penal internacional en esta dirección, al cuestionar las fronteras del derecho penal internacional (MOYN, 20I6).

Moyn sostiene que el derecho penal internacional cambió radicalmente su foco a principios de la década de I990, cuando se «reinventó»: desde entonces, su preocupación han sido exclusivamente las atrocidades, mientras que en sus orígenes su principal preocupación era la agresión (en términos generales, el recurso injustificado al uso de la fuerza). En la visión de Moyn, el derecho penal internacional ha cambiado tanto que resulta imposible defender la narrativa progresiva tradicional de la disciplina.

La máxima aspiración del progresismo legalista internacional hasta, al menos, la década de 1960_-argumenta Moyn — fue establecer mecanismos para limitar el recurso a la guerra ${ }^{6}$. Para demostrar este punto, Moyn destaca importantes desarrollos desde mediados del siglo xix, incluyendo los incansables esfuerzos para lograr

6] En este punto, Moyn se concentra en una corriente del Atlántico Norte. Para una perspectiva desde el sur, véase, por ejemplo, ESLAVA ET AL., 2017, sobre la Conferencia de Bandung de 1955 y los diversos proyectos políticos para la descolonización en el sur global. 
la prohibición de la guerra en el período de entreguerras (MOYN, 20I6: 8-I4; véase también HATHAWAY Y SHAPIRO, 20I7, y la crítica contemporánea de Carl SCHMITT, 2006). Desde esta perspectiva, Moynse concentra en los mismos eventos que la narrativa tradicional —Núremberg y Tokio, Eichmann y los ad hoc —, pero cuenta una historia diferente. El derecho penal internacional, en sus orígenes, buscó responder (o mostrarse como una respuesta) a esta gran demanda progresista: poner fin a la guerra. De hecho, recuerda Moyn, el foco de Núremberg fue la agresión.

Luego, aunque en línea con la «teoría de la interrupción» durante la Guerra Fría, Moyn señala que los desarrollos posteriores a Tokioberg (sIMPson, 20I6:3) —los juicios subsiguientes y Eichmann - no tuvieron mayor impacto en la agenda del derecho penal internacional ni lograron situar la atención global en las atrocidades (MOYN, 20I6: 20-2I). El desplazamiento ocurrió, según Moyn, gracias a la conciencia tardía sobre el Holocausto, en las décadas de 1960 y 1970 (MOYN, 20I6: 2I-28). En el derecho penal internacional — argumenta- este cambio se materializó a partir de 1990, cuando el final de la guerra fría permitió el establecimiento de nuevos tribunales penales internacionales (MOYN, 20I6: 28). Ni los ad hoc ni la Corte Penal Internacional se preocuparían por el delito de agresión; desde entonces, todo sería genocidio, crímenes de lesa humanidad y crímenes de guerra.

De este modo, Moyn enfrenta directamente a la narrativa tradicional, a la que critica por presentar al derecho penal internacional como «recorriendo un camino allanado, en lugar de una regresión absoluta o, cuando menos, un cambio masivo" (MOYN, 20I6: 2). El desafío de Moyn no tiene implicancias exclusivamente académicas: la reciente reconstrucción de la disciplinademuestra que el futuro del derecho penal internacional está abierto y que, como giró de la agresión a las atrocidades, su foco podría volver a cambiar en un futuro cercano.

\section{TWAIL}

Para los académicos TWAIL, la historia del derecho internacional es especialmente importante. TWAIL no es un método de investigación, sino un movimiento académico-político, que comprende diversos métodos y perspectivas, y comparte una sensibilidad y un interés por la forma en que el derecho internacional se experimenta y se piensa en el sur global (véase ANGHIE Y CHIMNI, 2003; ESLAVA Y PAHUJA, 2OI2), prestando atención a la relación entre el derecho internacional y el racismo estructural (véase KNOX, 20I5), la violencia (ANGHIE Y CHIMNI, 2003: 
77-79), el género, y la clase; y enfatizando los orígenes y la naturaleza colonialista del derecho internacional (FAKHRI, 20I2; véase ANGHIE, 2005).

Recientemente, Vasuki Nesiahtrazó una aproximación TWAIL a la historia del derecho penal internacional (NESIAH, 2OI6). Nesiah sostiene que la historia del derecho penal internacional es mucho más compleja que la que han contado los trabajos académicos más influyentes, fundamentalmente el libro de Gary Bass (NESIAH, 20I6: 96; véase, BASs, 2000). Contra ellos, Nesiah organiza su trabajo alrededor de dos argumentos centrales.

En primer lugar, Nesiah argumenta que las en las que se buscó obtener justicia internacional produjeron al menos tanta impunidad como antiimpunidad (NESIAH, 20I6: 96). La autora intenta demostrar esta hipótesis concentrándose en los eventos más famosos en la historia del derecho penal internacional, en los cuales — sostiene- los actores que promovieron las persecuciones penales aseguraron su propia impunidad por otros medios. Este punto comprende la habitual crítica tu quoque, notablemente expuesta por el Juez Pal en Tokio: ¡con qué legitimidad pueden los Aliados, tras el lanzamiento de las dos bombas atómicas, juzgar penalmente a agentes japoneses por la comisión de crímenes internacionales? (véase KOPELMAN, I99I: 36-38). Pero además de esta crítica — que se preocupa por quiénes son acusados por el derecho penal internacional—, el argumento de Nesiah se preocupa también por el qué: qué tipo de acciones son ignoradas e invisibilizadas por la narrativa tradicional. Por ejemplo, Nesiah cuestiona que Gary Bass retrate a los Aliados como loables promotores de la justicia internacional por intentar juzgar al Káiser tras la Gran Guerra — en sintonía con la narrativa del manual—e ignore que lo que realmente estaba en juego era el acaparamiento de tierras que estos estados llevaron a cabo tras la derrota de las Potencias Centrales (NESIAH, 2OI6: IO3-IO4).

En segundo lugar, en lo que constituye su argumento más novedoso, Nesiah sostiene que el modo en que los conceptos de justicia internacional y antiimpunidad han sido construidos ha contribuido a establecer una estructura de gobernanza global explotadora y promotora de desigualdad (NESIAH, 20I6). Ella argumenta que el retrato que la literatura realiza de Núremberg - una «oda a la gobernanza global liberal»— opera como una defensa militante del «orden mundial de posguerra y su apelación a la legitimidad universalista» (NESIAH, 20I6: IO7-IO8). Este respaldo al rol de los Aliados en la construcción del nuevo orden se extiende más allá de Núremberg, puesto que en el mismo período fueron establecidas las Naciones Unidas y el sistema de Bretton Woods. 
Al poner el foco en la economía política y el rol del imperialismo en la construcción del derecho penal internacional, la crítica historiográfica de Nesiah muestra el potencial de una aproximación TWAIL a la historia del derecho penal internacional. El argumento de Nesiah, como el de Moyn, no está libre de problemas: la relación entre Bretton Woods y el derecho penal internacional parece reclamar una investigación histórica algo más detallada ante un cierto riesgo de atribuir culpa por asociación. Sin embargo, esta intervención muestra lo lejos que la nueva literatura alrededor del giro histórico puede llevar a un campo moldeado por una narrativa de manual.

\section{DISCUTIENDO UNA AUSENCIA: AMÉRICA LATINA Y LA PREHISTORIA DEL DERECHO PENAL INTERNACIONAL}

Entre las muchas ausencias en la narrativa del manual del derecho penal internacional (véase HELLER Y SIMPSON, 2OI3; BERGSMO ET AL., 2OI4), quiero concentrarme en una: la de las discusiones, respuestas y juicios por violaciones de los derechos humanos cometidas por las dictaduras militares durante las transiciones democráticasen la década de 1980. Existen respuestas y argumentos convencionales para explicar algunas de estas ausencias. Explorar esta exclusión y estas razones permite desarrollar y contribuir a las perspectivas críticas que el giro histórico ha comenzado a ofrecer sobre la historiografía y la política del derecho penal internacional.

Quizás la ausencia más notable en esta dirección sea la política de rendición de cuentas por violaciones masivas de derechos humanos del gobierno de Raúl Alfonsín (1983-1989) en Argentina. El evento más significativo de esta política fue el Juicio a las Juntas ante la Cámara Nacional de Apelaciones en lo Criminal y Correccional Federal 7 . En I985, el tribunal condenó a cinco de los nueve militares que integraron las tres primeras Juntas que gobernaron al país durante la última dictadura militar entre 1976 y 1983, es decir, hasta dos años antes del dictado de la sentencia. Luego de este juicio, la justicia continuó investigando y condenando a oficiales de menor rango. Eventualmente, la lucha contra la impunidad cedería terreno frente a otras presiones, y llegarían las leyes de Punto Final y Obediencia

7] Cámara Nacional de Apelaciones en lo Criminal y Correccional Federal, "Causa n $13 / 84$ (Juicio a las Juntas Militares)», sentencia del 09/12/1985. 
Debida. De todos modos, para el final del gobierno de Alfonsín, la política gubernamental produjo, además del Juicio a las Juntas, la investigación y el informe de la CONADEP (COMISIÓN NACIONAL SOBRE LA DESAPARICIÓN DE PERSONAS, I984), mientras que otras quince personas responsables por el terrorismo de estado fueron condenadas (NINO, I995: II6; sobre el contexto histórico de la política de derechos humanos del gobierno de Alfonsín, véase NINO, I995: 4I-IO4). En su célebre estudio sobre cómo responder a las atrocidades del pasado, Carlos Nino sostuvo a principios de los 1990 que: «ha habido pocas instancias en la historia del mundo [...] de persecución de aquellos responsables por violaciones masivas de derechos humanos. Argentina hizo justamente eso [... ]» (NINO, I995: I86). En 1985, la noción de que el castigo penal era la respuesta adecuada para las violaciones masivas a los derechos humanos no estaba extendida; la idea de que era la respuesta obligatoria, en tanto, era casi inexistente (ENGLE, 2015: I073-IO74).

Podría objetarse que esta exclusión es fácilmente justificable desde lo jurídico: los procesos penales en Argentina de la década de 1980 constituyeron una instancia de aplicación de derecho penal interno por parte de un tribunal doméstico, por lo que no tendría sentido analizarlo desde una perspectiva de derecho penal internacional. Efectivamente, aunque la definición de derecho penal internacional y el límite preciso de sus alcances han sido objeto de mucho debate (véase, por ejemplo, SCHWARZENBERGER, I95O; O'KEEFE, 2OI5: 47-84; CHEHTMAN, 2OI7; HELLER, 2OI7), la mayoría de las definiciones convencionales excluirían a un proceso en el que no se investiguen crímenes internacionales — por ejemplo, genocidio, crímenes de lesa humanidad o crímenes de guerra- Los responsables por las violaciones de derechos humanos durante la dictadura fueron, en cambio, condenados como autores de crímenes domésticos — notablemente; homicidios, tormentos y privación ilegítima de la libertad-y no de crímenes internacionales ${ }^{8}$. Gary Bass ofrece, de hecho, un argumento similar, aunque no jurídico, para explicar por qué no incluye

8] El derecho internacional fue, en cambio, central para las persecuciones que se dieron a partir de 2001, para sortear obstáculos tales como la prescripción de los delitos o las amnistías previamente convalidadas por la Corte Suprema. Véanse las decisiones de la Corte Suprema de Justicia de la Nación en CSJN,, 14 de junio de 2005, «Simón», disponible en: https://sjconsulta.csjn.gov.ar/sjconsulta/ documentos/verDocumentoByldLinksJSP.html?idDocumento=5863381; CSJN, 13 de julio de 2007, «Mazzeo», disponible en: http://sjconsulta.csjn.gov.ar/sjconsulta/documentos/verDocumentoByldLinksJSP.html?idDocumento $=6305031$. 
"casos como los de Chile o Sudáfrica» en su historiade la justicia internacional (BASS, 2000: 6). En estos casos — explica Bass — tuvieron lugar acalorados debates sobre la relación entre el derecho penal, la justicia y la paz, pero exclusivamente dentro de las fronteras nacionales (BASS, 2000: 6).

Desde esta perspectiva, podría argumentarse que la política del gobierno de Alfonsín puede ser analizada desde otras disciplinas, como el derecho penal o la justicia transicional (véase, por ejemplo, TeITEL, 2000), pero no desde el derecho internacional. Con el mismo argumento podrían justificarse otras exclusiones de los procesos de democratización, como los casos uruguayos y chilenos. En el caso uruguayo, durante el gobierno de Julio María Sanguinetti, el Congreso sancionó la Ley de Caducidad en 1986, que impidió que fueran llevados a juicio los autores de violaciones a los derechos humanos durante la dictadura. En 1989, se celebró un referéndum que decidió no revocar esta ley (véase BURT ET AL., 20I3). Los desarrollos en Chile que quedarían desplazados de acuerdo con esta objeción incluyen la Ley de Amnistía de la dictadura de Pinochet, el establecimiento de la Comisión Nacional de Verdad y Reconciliación, y el Caso Letelier (véase ZALAQueTt, I992; CORREA, I992; COLLINS, 2OIO).

Sin embargo, la objeción presenta costos significativos. En particular, expone a la historia del derecho penal internacional como una predominantemente preocupada por eventos y no por causalidades de largo plazo. Una perspectiva estrictamente jurisdiccional como la que subyace esta objeción implica un compromiso con una historia en la que incidentes específicos — un determinado tribunal o un determinado juicio — «son capturados y delimitados, separados de la caótica continuidad temporal y de la contingencia espacial, convirtiéndose en emblemas de una evolución organizada cronológicamente y en busca de una historia coherente — descriptiva antes que analítica- de un orden de derecho internacional que toma forma» (TALLGREN, 20I4: xix). Si recién a partir del final de la Guerra Fría el derecho penal internacional comenzó a ser utilizado principalmente para castigar atrocidades (MOYN, 2OI6; véase MÉGRET, 2OI8), ¿qué clase de historiografía no esencialista puede ignorar instancias de persecuciones penales por la comisión de atrocidades, y debates y luchas relacionadas, que precedieron inmediatamente a este giro?

El argumento aquí no es que el "giro hacia la atrocidad» sea producto de los desarrollos latinoamericanos, sino que el desinterés disciplinario señala una falencia. Estos desarrollos podrían formar parte de una prehistoria del (nuevo) derecho penal internacional, que deben ser estudiados para entender mejor sus condiciones 
de posibilidad, tensiones, límites y posibilidades (véase MOYN, 2017: 314-315). Por ejemplo, en su intervención en la discusión historiográfica sobre los orígenes de los derechos humanos, Stefan-Ludwig Hoffmann analiza conjuntamente desarrollos vinculados al derecho internacional de los derechos humanos, al derecho del uso de la fuerza y al derecho penal internacional, para argumentar que puede hablarse por primera vez de derechos humanos como "concepto básico» a partir de la década de 1990 (hoffmann, 20I7).

Kathryn Sikkink ha hecho un argumento mucho más ambicioso en una dirección conexa (sIKKINK, 2OII). Desde una perspectiva constructivista de las relaciones internacionales, Sikkink argumenta que la experiencia argentina fue determinante para la emergencia de un sistema descentralizado e interactivo de rendición de cuentas a partir de la década de 1990, definido por la actuación de tribunales penales internacionales — notablemente, la Corte Penal Internacional- y tribunales domésticos aplicando normas de derecho internacional — por ejemplo, los procesos de jurisdicción universal—. Su intervención, desde la frontera de la disciplina, marca un contraste con la narrativa del manual del derecho penal internacional al demostrar la necesidad de analizar conjuntamente desarrollos locales e internacionales. Su argumento, en el contexto de un libro que se propone demostrar la importancia de las persecuciones penales en la protección de los derechos humanos, deja, sin embargo, algunos interrogantes importantes, que una historiografía conjunta del derecho penal internacional y esta prehistoria latinoamericana debería abordar; en particular: ¿cómo se relaciona, en el contexto latinoamericano, la emergencia del proyecto de la responsabilidad penal con otras visiones de justicia? (MOYN, 20I4:63; sobre discusiones similares en la nueva historiografía de los derechos humanos, véase MOYN, 2OIO; MARKS, 2OI3; WHYTE, 2OI8).

Al mismo tiempo, la objeción se apoya en una distinción algo inequívoca entre lo internacional y lo doméstico. Los casos de Chile y Argentina ilustran, sin embargo, la fluidez de esta relación. La Comisión Interamericana de Derechos Humanos realizó visitas in loco sobre la situación de derechos humanos en ambos países durante sus respectivas dictaduras militares. En su informe del 25 de octubre de 1974, tras la visita a Chile, la Comisión concluyó que el régimen de la Junta Militar había incurrido en "gravísimas violaciones de derechos humanos» (CIDH, 1974), incluyendo el derecho a la vida, el derecho a la integridad personal y el derecho a la libertad personal (CIDH, I974: capítulo XVI). Ante esta situación, la Comisión realizó en su informe un número de recomendaciones al régimen, 
incluyendo «la realización de una investigación exhaustiva, minuciosa, rápida e imparcial» de ciertos hechos, mayormente relacionados con actos de tortura (CIDH, I974: capítulo XVII, párr. 2.I). Notablemente, la Comisión destacó que: «[e]sta misión debe consistir en la identificación precisa de los responsables de los hechos indicados en esta recomendación, para su ulterior juzgamiento por las autoridades judiciales ordinarias de Chile» (CIDH, I974: capítulo XviI, párr. 2.I). La Comisión volvió a recomendar la respuesta penal, utilizando un lenguaje similar, en otro informe sobre la situación de derechos humanos en Chile en $1977^{9}$, y en informes posteriores sobre El Salvador ${ }^{10}$ y Haití ${ }^{11}$. En palabras del entonces comisionado estadounidense Tom Farer, la Comisión se reconvirtió en una "agencia acusatoria» (FARER, I997: 5I2). En 1979, los comisionados visitaron Argentina para verificar el cumplimiento de los derechos humanos por parte de la dictadura militar que gobernaba al país desde 1976. En su informe de I980 (CIDH, I980), la Comisión recomendó a la dictadura argentina «enjuiciar y sancionar, con todo el rigor de la ley, a los responsables» de las muertes imputadas a autoridades públicas ${ }^{12} \mathrm{y}$ de las torturas y otros apremios ilegales. ${ }^{13}$ El recurso al derecho penal en los informes de la Comisión en los setenta todavía espera un análisis histórico más profundo, pero la intervención es suficiente para sugerir, como mínimo, que los casos de Chile y Argentina no pueden excluirse como casos simplemente domésticos (sobre la influencia de actores internacionales en la política de Alfonsín y el Juicio a las Juntas véase SIKKINK, 2OII: capítulo 3; MORENO OCAMPO, 2OI4: capítulo II; véase también HUNEEUS, 20I3, sobre los sistemas regionales de derechos humanos y el «derecho penal internacional por otros medios»).

9] La Comisión recomendó: «[a]doptar una política adecuada y firme de averiguación, procesamiento y castigo, si fuera el caso, de aquellas autoridades que abusan de su poder y sometan a los detenidos a tratamientos inhumanos, contrarios al derecho a la integridad personal» (CIDH, 1977, capítulo XII). 10] La Comisión recomendó: «[e]mpeñarse en que se investiguen las denuncias sobre personas muertas, detenidas, torturadas o desaparecidas con posterioridad a su detención, así como investigar, enjuiciar y hacer que se sancionen a las autoridades responsables por tales actos» (CIDH, 1978, conclusiones y recomendaciones).

11] La Comisión recomendó: «[i]nvestigar y sancionar a los responsables de las numerosas violaciones al derecho a la vida y a la integridad física» (CIDH, 1979, recomendaciones).

12] $\mathrm{CIDH}, 1980$, Conclusiones y recomendaciones, Recomendaciones, párrafo 1 .

13] $\mathrm{CIDH}, 1980$, Conclusiones y recomendaciones, Recomendaciones, párrafo 6. 
La exclusión de la prehistoria latinoamericana — ahora más difícil de justificarseñala una historia del derecho penal internacional excesivamente preocupada por el precedente, tanto en un sentido técnico como en un sentido figurado. Por un lado, refleja una historia estructurada alrededor de antecedentes profesionalmente relevantes, normas y sentencias que pueden ser analizadas y citadas en el ejercicio profesional de la profesión, y en la producción académica orientada hacia la interpretación del derecho con miras a su aplicación profesional. Por el otro, la exclusión sugiere una historiogra fíaselectiva, especialmente interesada en instancias concretas de éxito.

Los desarrollos latinoamericanos durante la democratización no encajan fácilmente en esta búsqueda de precedentes. En Uruguay, un Congreso democrático sancionó la Ley de Caducidad y el voto por la revocación fue derrotado en un referéndum tres años después. En Chile, la Ley de Amnistía de Pinochet fue uno de los obstáculos para la persecución penal de los crímenes cometidos por la dictadura hasta el año 1998. Incluso el caso argentino reclama cierta cautela. El propio Nino, quien destacó la política del gobierno de Alfonsín como innovadora y exitosa, concluyó, sobre la base de su estudio sobre Argentina en "Juicio al mal absoluto», que una obligación internacional de perseguir penalmente violaciones a los derechos humanos podría desestabilizar no sólo los procesos de transición democrática, sino incluso los propios procesos de promoción de las persecuciones penales, al establecer estándares difíciles de cumplir como el de castigar a todos los que merezcan castigo (NINO, I995: I86-I87; sobre las tensiones entre democracia, derecho internacional y castigo, en el contexto de violaciones a los derechos humanos en América Latina, véase Gargarella, 20I5). La política del gobierno de Alfonsín fue, para Nino, tanto exitosa como limitada, y el "producto de un equilibrio delicado» de factores políticos, jurídicos y morales (NINO, I995: I07-I86). Esta experiencia no puede reducirse a un precedente exitoso más en la cronología del derecho penal internacional. El paradigma actual del «derecho a la rendición de cuentas» contrasta con los influyentes argumentos con miras al futuro para justificar los juicios del propio Nino y de Jaime Malamud, asesores de Alfonsín (TEITEL, 20I9).

Por último, y de modo más general, esta exclusión ilustra el eurocentrismo dominante en la historiografía del derecho penal internacional. Los silencios, es cierto, son muchos, y abarcan también diversos desarrollos en Asia y en África (véase HELLER Y SIMPSON, 2OI3; BERGSMO ET AL., 2OI4). En este sentido, la exclusión 
simplemente subraya el problema del eurocentrismo en la historia y el presente del derecho internacional (sobre el eurocentrismo en el derecho internacional, véase, por ejemplo, GATHII, I998; KOSKENNIEMI, 2OII; BECKER LORCA, 2OI2).

Cabe aquí, sin embargo, una advertencia. La respuesta a la exclusión no debe ser llenar los vacíos y silencios de forma mecánica (TALLGREN, 20I4: xxviii). Esta alternativa puede parecer especialmente atractiva en el contexto latinoamericano, donde los juristas han recurrido históricamenteal lenguaje de la «contribución latinoamericana» para destacar el rol regional en la construcción del derecho internacional (BECKER LORCA, 2006: 290-293). Esta narrativa, sin embargo, no denuncia el eurocentrismo, sino que reafirma su universalidad (BECKER LORCA, 2006: 290-293; sobre la crítica al "contribucionismo" y la historia del derecho internacional en África, véase GATHII, 2008). He argumentado que la exclusión de esta prehistoria latinoamericana ilustra algunos problemas en la historiografía tradicional del derecho penal internacional: su desinterés por las causalidades de largo plazo, su apoyo en una distinción binaria entre lo internacional y lo doméstico, su inclinación hacia la búsqueda de precedentes útiles (en sentido técnico como jurisprudencia y antecedentes jurídicamente relevantes, y en sentido metafórico como historias de éxito) y su eurocentrismo. En gran medida, este es un punto de partida y no uno de llegada. Sobre esta base, parece más prometedor preguntarse cómo y por qué determinadas doctrinas o prácticas emergieron en la región — por ejemplo, el enlace entre los derechos internacional de los derechos humanos y el derecho penal—, con qué efectos — por ejemplo, descomprimiendo los intentos de obtener reformas económicas y políticas más estructurales (véase ARTHUR, 2009; ALVIAR Y ENGLE, 20I6) - y qué lecciones ofrece esta experiencia particular para entender la operación del derecho penal internacional que destacar el rol de América Latina en la construcción del presunto lenguaje universal del derecho penal internacional. La historiografía reciente del derecho internacional en América Latina sirve de inspiración, al abordar con sofisticación la relación entre el derecho internacional y la política regional, y las tensiones entre el universalismo, el regionalismo y el imperialismo en la operación histórica del derecho internacional en la región (véase OBREGÓN, 2006; BECKER LORCA, 2OI4; SCARFI, 2OI7). 


\section{CONCLUSIÓN}

A partir de las transformaciones asociadas con el giro histórico, el estudio del derecho internacional se ha vuelto mucho más receptivo a miradas históricas e historiográficas, que han abierto espacios para criticar los postulados celebratorios y los usos de la historia en el derecho internacional. Esta renovación presenta un desafío al derecho penal internacional, cuyos promotores a menudo defienden apoyándose en una historia que - he argumentado- es tan grandiosa como simplista. He ilustrado el potencial de esta renovación al destacar perspectivas contraselectivas, reconceptualizadoras y tercermundistas de la historia del derecho penal internacional. Estas críticas historiográficas tienen crucial importancia para el presente, en tanto facilitan el análisis de la operación contemporánea del derecho penal internacional, colocando las críticas a su eurocentrismo, su economía política y su imperialismo en primer plano, y desnaturalizando su misión y sus efectos.

Entre las muchas ausencias de la narrativa del manual del derecho penal internacional se encuentran los desarrollos latinoamericanos durante las transiciones a la democracia a partir de la década de I980, que podrían constituir una prehistoria del derecho penal internacional concentrando en la persecución y prevención de atrocidades, asociado a los tribunales penales internacionales establecidos tras el final de la Guerra Fría. He explorado esta exclusión en particular y argumentado - en línea con las revisiones críticas - que retrata ciertas deficiencias en la historiografía tradicional de la disciplina. Una implicancia de este argumento es la justificación de una mayor atención a los desarrollos en materia de antiimpunidad en América Latina desde la perspectiva de la historia del derecho penal internacional (más allá de la justicia transicional y las relaciones internacionales). No se trata, sin embargo, sólo de llenar los vacíos, sino de recuperar el poder disruptivo de estos desarrollos para iluminar el pasado, analizar críticamente el presente y reimaginar el futuro del derecho penal internacional. 


\section{Referencias bibliográficas}

AMBOS, KAl (2013): Treatise on International Criminal Law, Oxford University Press, Oxford.

ANGHIE, ANTONY (2005): Imperialism, Sovereignty and the Making of International Law, Cambridge University Press.

ANGHIE, ANTONY Y CHIMNI, B.S. (2003): «Third World Approaches to International Law and Individual Responsibility in Internal Conflict», en: Chinese Journal of International Law, n² 2.1.

ARENDT, HANNAH (1963): Eichmann in Jerusalem, Viking Press, Nueva York.

ARTHUR, PAIGE (2009): «How ‘Transitions〉 Reshaped Human Rights: A Conceptual History of Transitional Justice», en: Human Rights Quarterly, n 31.2. ALVIAR, HELENA Y ENGLE, KAREN (2016): «The Distributive Politics of Impunity and Anti-Impunity: Lessons from Four Decades of Colombian Peace Negotiations» en: Karen Engleet al., Anti-Impunity and the Human Rights Agenda, Cambridge University Press.

BANTEKAS, ILIAS Y NASH, SUSAN (2007): International Criminal Law, Routledge.

BARRETO, JOSÉ MANUEL (2013): Human Rights from a Third World Perspective, Cambridge Scholars Publishing.

BARRET0, JOSÉ MANUEL (2015): Six Books: International Law, Human Rights and the Politics of the Turn to History, Critical Legal Thinking.

BASS, GARY (2000): Stay the Hand of Vengeance, Princeton University Press.

BASSIOUNI, CHERIF (2013): Introduction to International Criminal Law, Brill Nijhoff.

BECKER LORCA, ARNULF (2006): «International Law in Latin America or Latin American International Law? Rise, Fall, and Retrieval of a Tradition of Legal Thinking and Political Imagination», en: Harvard International Law Journal, n 47.1.

BECKER LORCA, ARNULF (2012): «Eurocentrism in the
History of International Law» en: Bardo Fassbender y Anne Peters, The Oxford Handbook of the History of International Law.

BECKER LORCA, ARNULF (2014): Mestizo International Law, Cambridge University press.

BERGSMO, MORTEN ET AL. (2014): Historical Origins of International Criminal Law: volúmenes 1-5, TOAEP. BERMAN, NATHANIEL (1992): «Modernism, Nationalism, and the Rhetoric of Reconstruction", en: Yale Journal of International Law \& the Humanities, $\mathrm{n}^{\circ} 4.2$.

BIANCHI, ANDREA (2017): International Law Theories: An Inquiry into Different Ways of Thinking, Oxford University Press.

BURT, J0-MARIE ET AL. (2013): «Civil Society and the Resurgent Struggle against Impunity in Uruguay (1986-2012)», en: The International Journal of Transitional Justice, $\mathrm{n}^{\circ} 7$.

CASSESE, ANTONIO (2008): International Criminal Law, Oxford University Press.

CHEHTMAN, ALEJANDRO (2017): «A Theory of International Crimes: Conceptual and Normative Issues», Oxford Handbook of International Criminal Law (en prensa).

COLLINS, CATH (2010): «Human Rights Trials in Chile during and after the «Pinochet Years ' ", en: The International Journal of Transitional Justice, vol. 4. COMMISSION ON THE RESPONSIBILITY OF THE AUTHORS OF THE WAR AND ON ENFORCEMENT OF PENALTIES: «Report Presented to the Preliminary Peace Conference», American Journal of International Law, vol. 14. COMISIÓN INTERAMERICANA DE DERECHOS HUMANOS (CIDH) (1974): «Informe sobre la Situación de los Derechos Humanos en Chile», OEA/Ser.L/V/II.49 doc. 21. COMISIÓN INTERAMERICANA DE DERECHOS HUMANOS (CIDH) (1977): «Tercer Informe sobre la Situación de los Derechos Humanos en Chile», OEA/Ser.L/V/ II.40 doc. 10 . 
COMISIÓN INTERAMERICANA DE DERECHOS HUMANOS (CIDH) (1978): «Informe sobre la Situación de los Derechos Humanos en El Salvador», OEA/Ser.L/V/ II.46 doc. 23 rev. 1.

COMISIÓN INTERAMERICANA DE DERECHOS HUMANOS (CIDH) (1979): «Informe sobre la Situación de los Derechos Humanos en Haití», OEA/Ser.L/V/II.46 doc. 66, rev. 1.

COMISIÓN INTERAMERICANA DE DERECHOS HUMANOS (CIDH) (1980): «Informe sobre la Situación de los Derechos Humanos en Argentina», OEA/Ser.L/V/ II.49 doc. 19.

CRAWFORD, JAMES (2012): Brownlie's Principles of International Law, Oxford University Press.

CRYER, ROBERT ET AL. (2014): An Introduction to International Criminal Law and Procedure, Cambridge University Press.

ENGLE, KAREN (2015): «Anti-Impunity and the Turn to Criminal Law in Human Rights», en: Cornell Law Review, n 100.5.

ESLAVA, LUISET AL. (2017): Bandung, Global History, and International Law: Critical Pasts and Pending Futures, Cambridge University Press.

ESLAVA, LUIS Y PAHUJA, SUNDHYA (2012): «Beyond the (Post)Colonial: TWAIL and the Everyday Life of International Law», en: Journal of Law and Politics in Africa, Asia and Latin America, $\mathrm{n}^{\circ}$ 45. 2. FAKHRI, MICHAEL (2012): "Questioning TWAIL's Agenda», en: Oregon Review of International Law, vol. 14.1.

FARER, TOM (1997): «The Rise of the Inter-American Human Rights Regime: No Longer a Unicorn, Not Yet an Ox», en: Human Rights Quarterly, n 19.3. GATHII, JAMES THUO (2018): «A Critical Appraisal of the International Legal Tradition of TaslimOlawale Elias», en: Leiden Journal of International Law, $\mathrm{n}^{\circ} 21$.

GARGARELLA, ROBERTO (2015): «La democracia frente a los crímenes masivos: una reflexión a la luz del caso Gelman», en: Revista Latinoamericana de Derecho Internacional, $\mathrm{n}^{\circ} 2$.

HALME-TUOMISAARI, MIIA Y SLOTTE, PAMELA (2015): «Revisiting the origins of human rights: introduction», en: Pamela Slotte y Miia Halme-Tuomisaari (eds.), Revisiting the Origins of Human Rights, Cambridge University Press.

HATHAWAY, OONA Y SHAPIRO, SCOTT (2017): The Internationalists, Allen Lane.

HELLER, KEVIN (2011): The Nuremberg Military Tribunals and the Origins of International Criminal Law, Oxford University Press.

HELLER, KEVIN (2017): «What Is an International Crime? (A Revisionist History)», en: Harvard International Law Journal, n 58.2.

HELLER, KEVIN Y SIMPSON, GERRY (2013): The Hidden Histories of War Crimes Trials, Oxford University Press.

HOFFMANN, STEFAN-LUDWIG (2017): «Derechos humanos e historia», Revista Latinoamericana de Derecho Internacional, $\mathrm{n}^{\circ} 6$.

HULL, ISABEL (2014): A Scrap of Paper: Breaking and Making International Law During the Great War, Cornell University Press.

HUNEEUS, ALEXANDRA (2013): «International Criminal Law by Other Means: The Quasi-criminal Jurisdiction of the Human Rights Courts», en: American Journal of International Law $\mathrm{n}^{\circ}$ 107.1.

JENSEN, STEVEN (2016): The Making of International Human Rights: The 1960s, Decolonization, and the Reconstruction of Global Values, Cambridge University Press.

KENNEDY, DAVID (1987): «The Move to Institutions», en: Cardozo Law Review, nº 8.

KNOX, ROB (2015): «Race, Racialisation and Rivalry in the International Legal Order», en: Alexander Anievaset al. (eds.), Race and Racism in Inter- 
national Relations: Confronting the Global Colour Line, Routledge.

KOPELMAN, ELIZABETH (1991): «Ideology and international law: the dissent of the Indian justice at the Tokyo War Crimes Trial», NYU Journal of International Law and Politics, $\mathrm{n}^{\circ} 23.2$.

KOSKENNIEMI, MARTTI (2001): The Gentle Civilizer of Nations, Cambridge University Press.

KOSKENNIEMI, MARTTI (2011): «Histories of International Law: Dealing with Eurocentrism», Rechtsgeschichte, $\mathrm{n}^{\circ} 19$.

KOSKENNIEMI, MARTTI (2018): «Less is More: Legal Imagination in Context», Leiden Journal of International Law, n 31.3.

LANG, ANDREW Y MARKS, SUSAN (2017): "Even the Dead Will Not Be Safe International Law and the Struggle over Tradition» en: Wouter Werner et al., The Law of International Lawyers: Reading Martti Koskenniemi, Cambridge University Press. LUBAN, DAVID (2013): «After the Honeymoon: Reflections on the Current State of International Criminal Justice», en: Journal of International Criminal Justice, $\mathrm{n}^{\circ}$ 11.3.

MARKS, SUSAN (2013): «Four human rights myths» en: Kinley, David et al. (eds.), Human Rights: Old Problems, New Possibilities, Edward Elgar Publishing.

MÉGRET, FRÉDÉRIC (2002): «The Politics of International Criminal Justice», en: European Journal of International Law no 13.5 .

MÉGRET, FRÉDÉRIC (2018): «International Criminal Justice as a Peace Project», en: European Journal of International Law, n 18.3 .

MORENO OCAMPO, LUIS (2014): Cuando el poder perdió el juicio, Capital Intelectual, Buenos Aires. MOYN, SAMUEL (2010): The Last Utopia, Harvard University Press, Cambridge.

MOYN, SAMUEL (2012): "Substance, Scale, and Salience: The Recent Historiography of Human
Rights», en: Annual Review of Law and Social Science, $\mathrm{n}^{\circ} 8$.

MOYN, SAMUEL (2014): Human Rights and the Uses of History, Verso.

MOYN, SAMUEL (2016): «From Aggression to Atrocity: Rethinking the History of International Criminal Law», Oxford Handbook of International Criminal Law (en prensa).

MOYN, SAMUEL (2017): «El final de la historia de los derechos humanos», en: Revista Latinoamericana de Derecho Internacional, $\mathrm{n}^{\circ} 6$.

MOYN, SAMUEL (2018): Not Enough: Human Rights in an Unequal World, Harvard University Press. NESIAH, VASUKI (2016): «Doing History with Impunity» en: Karen Engle et al. (eds.), Anti-Impunity and the Human Rights Agenda.

NINO, CARLOS SANTIAGO (1995): Radical Evil on Trial, Yale University Press.

NOUWEN, SARAH M.H. (2012): «Justifying Justice» en: James Crawford y Martti Koskenniemi (eds.), The Cambridge Companion to International Law, Cambridge University Press.

OBREGÓN, LILIANA (2006): «Between Civilisation and Barbarism: Creole interventions in international law», en: Third World Quarterly, vol. 27.5.

O'KEEFE, ROGER (2015): International Criminal Law, Oxford University Press.

ORFORD, ANNE (2013): «The Past as Law or History? The Relevance of Imperialism for Modern International Law» en: Toufayan, Mark et al. (eds.), International Law and New Approaches To The Third World, Société de Législation Comparée. ORFORD, ANNE (2017): «International Law and the Limits of History", en: Wouter Werner et al. The Law of International Lawyers: Reading Martti Koskenniemi, Cambridge University Press. PAL, RADHABINOD (1953): International Military Tribunal for the Far East: Dissentient Judgment, Sanyal. 
PITTS, JENNIFER (2017): «International relations and the critical history of International Law», en: International Relations, $\mathrm{n}^{\circ} 31.3$.

ROBERTSON, GEOFFREY (2012): Crimes Against Humanity: The Struggle For Global Justice, Penguin. SCARFI, JUAN PABLO (2017): «Del giro ético al historicista: el potencial y los límites de la perspectiva histórica en los derechos humanos y el derecho internacional», en: Revista Latinoamericana de Derecho Internacional, $\mathrm{n}^{\circ} 6$.

SCARFI, JUAN PABLO (2017): The Hidden History of International Law in the Americas: Empire and Legal Networks, Oxford University Press, Oxford. SCHABAS, WILLIAM (2016): "La banalidad de la justicia internacional», en: Revista Latinoamericana de Derecho Internacional, $\mathrm{n}^{\circ} 4$.

SCHEFFER, DAVID (2011): All the Missing Souls, Princeton University Press.

SCHMITT, CARL (2006): The Nomos of the Earth, Telos, Nueva York.

SCHWARZENBERGER, GEORG (1950): «The Problem of an International Criminal Law», en: Current Legal Problems, n 3.1 .

SIKKINK, KATHRYN (2013): La Cascada de la Justicia, Gedisa, Barcelona.

SIMPSON, GERRY (2004): Great Powers and Outlaw States, Cambridge University Press.

SIMPSON, GERRY (2007): Law, War and Crime, Polity. SIMPSON, GERRY (2013): «History of Histories» en: Kevin Jon Heller y Gerry Simpson (eds.), The Hidden Histories of War Crimes Trials, Oxford University Press.

SIMPSON, GERRY (2016): «Mutually Assured Cons- truction: Two Ways of Looking at the Cold War», manuscrito inédito.

SIMPSON, GERRY (2016): «Anti-anti-anti impunity», manuscrito inédito.

SKINNER, QUENTIN (1969): «Meaning and Understanding in the History of Ideas», en: History and Theory, no 8.1 .

TALLGREN, IMMI (2014): «Searching for the Historical Origins of International Criminal Law» en: Morten Bergsmo et al., Historical Origins of International Criminal Law: volume 3, TOAEP.

TEITEL, RUTI (2000): Transitional Justice, Oxford University Press, Oxford.

TEITEL, RUTI (2019): «iEl jurista global como un pedagogo? Ronald Dworkin en la Argentina postdictadura», en: Revista Latinoamericana de Derecho Internacional, nº 8.

UNGER, ROBERTO MANGABEIRA (2001): False Necessity, Verso.

VADI, VALENTINA (2017): «International law and its histories», en: Harvard International Law Journal, $n^{\circ} 58.2$.

VARADARAJAN, LATHA (2014): «The trials of imperialism: Radhabinod Pal's dissent at the Tokyo tribunal», en: European Journal of International Relations, $\mathrm{n}^{\circ} 21.4$.

WHYTE, JESSICA (2018): «Powerless Companions or Fellow Travellers?», en: Radical Philosophy, $n^{\circ} 202$.

ZALAQUETT, JOSÉ (1992): «Balancing Ethical Imperatives and Political Constraints: The Dilemma of New Democracies Confronting Past Human Rights Violations», en: Hastings Law Journal, n 43.6. 